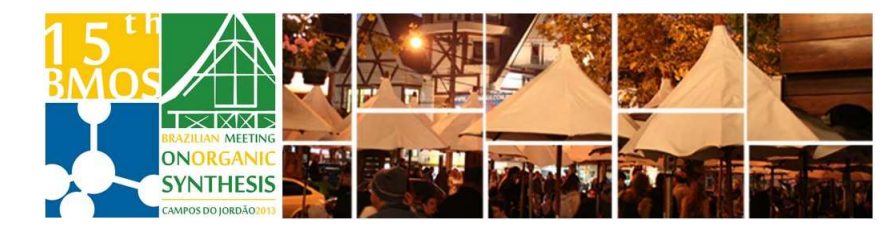

\title{
Methodological study of the classic Claisen rearrangement in Morita-Baylis-Hillman adducts
}

\author{
Tiago C. A. F. Rodrigues, Wender Alves da Silva* e Angelo H. L. Machado* \\ Campus Universitário Darcy Ribeiro, 4478, CEP 70904-970, Asa Norte, Brasília-DF \\ frodrigues07@gmail.com
}

Keywords: Claisen rearrangement, Morita-Baylis-Hillman adducts, pericyclic reaction

\section{INTRODUCTION}

Although the Claisen rearrangement has been discovered over 100 years ago, studies on its reaction mechanism, the use of catalysts and its application on Total Synthesis are still updated. There is only one example of classic Claisen rearrangement in Morita-Baylis-Hillman (MBH) adducts described in the literature. This example involves the synthesis of pilocarpine, a therapeutic agent used in the treatment of glaucoma. ${ }^{1}$

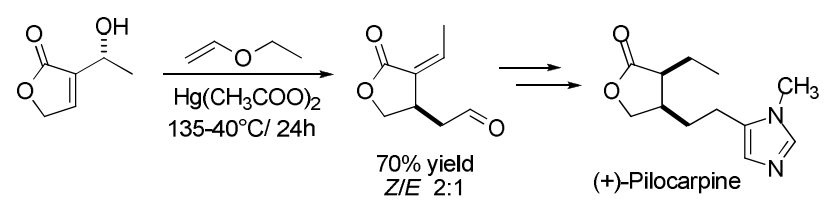

Scheme 1. Total synthesis of (+)-Pilocarpine - First issue of a classic Claisen rearrangement in $\mathrm{MBH}$ adduct. ${ }^{1}$

This paper aims to present our former results on the investigation of the classic Claisen rearrangement of $\mathrm{MBH}$ adducts.

\section{RESULTS AND DISCUSSION}

$\mathrm{MBH}$ adducts were prepared by the reaction between aliphatic and aromatic aldehydes and ethyl acrylate in the presence DABCO as described by Vasconcellos et al. ${ }^{2}$ Scheme 2 represents the general reaction and the aldehydes used with their respective yields.

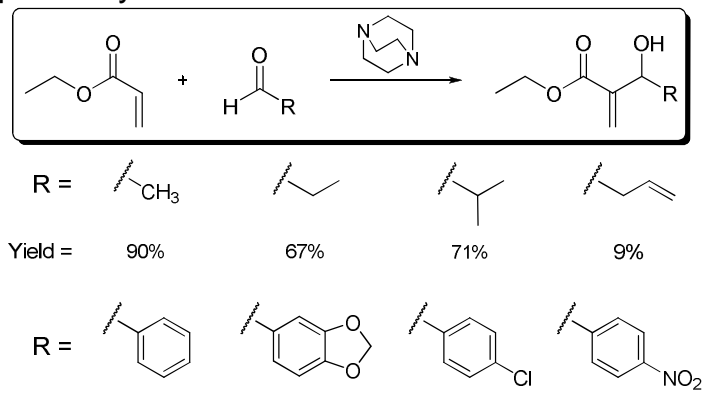

Yield $=\quad 28 \% \quad 17 \% \quad 73 \% \quad 25 \%$

Scheme 2. MBH adducts prepared in this work.

The $\mathrm{MBH}$ with $\mathrm{R}=\mathrm{CH}_{3}$ was treated with ethylvinylether and $\mathrm{Hg}(\mathrm{OAc})_{2}$, following the Kumar's et al work. ${ }^{3}$ The best experimental condition to affords the Claisen rearrangement was investigated by the screening of the temperature and the reaction time. The best conversion, up to $90 \%$, was obtained at $100{ }^{\circ} \mathrm{C}$ for 48 hours and the observed stereoselectivity was 3:1 favoring the $E$ isomer (Scheme 1).

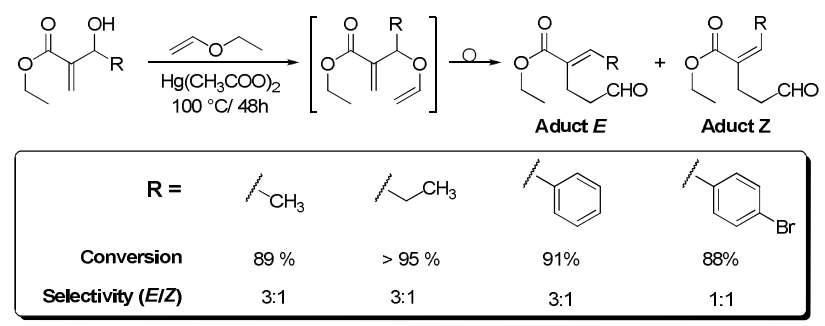

Scheme 3. Vinylation reaction followed by the classic Claisen rearrangement.

The standard reaction condition was also used to perform the Claisen rearrangement to other three $\mathrm{MBH}$ adducts. Conversion up to $90 \%$ was also obtained and the observed stereoselectivity was in the same sense favoring the $E$ isomer, except for $\mathrm{R}=4-\mathrm{BrPh}$.

Mass spectroscopy and ${ }^{1} \mathrm{H}$ NMR were used to evaluate the conversion and the selectivity of the rearrangement reactions. The analyses of $[3,3]-$ sigmatropic rearrangement for other adducts are in progress.

\section{CONCLUSION}

The observed stereoselectivities are in agreement to the former results reported by Buchi and co-workers were the $E$ isomer was obtained as the major one. This investigation of the scope of this reaction and its application on total synthesis of a-methylenelactones and 2,3-substituted piperidines are ongoing in our lab.

\section{ACKNOWLEDGEMENTS}

This paper was supported by CAPES and Universidade de Brasília.

\section{REFERENCES}

1 Horne, A. D.; Fugmann, B.; Yakushijin, K.; Buchi, G. J. Org. Chem.1993, $58,62-64$.

2 Junior, G. L. C; Oliveira, G. R. Subrinho, L. F.; Andrade, G. N.;

Vasconcellos, L. A. A. M. J. Braz. Chem. Soc. 2011, 22, 2220-2224.

${ }^{3}$ Srikrishna, A.; Yelamaggad, V. C.; Kumar, P. P. J. Chem. Soc. 1999, 2877-2881. 